embryonic development originates in part through endogenous biosynthesis in the neuroepithelium and in part through exogenous, maternal- or yolk sac-derived cholesterol transported on lipoproteins. The papers describing hedgehog processing and function ${ }^{1-4}$ provide a possible mol-

1. Chiang, C. et al. Nature $383,407-413$ (1996)

2. Porter, J.A., Young, K.E. \& Beachy, P.A. Science 274, 255-259 (1996)

3. Belloni, E. et al. Nature Genet. 14, 353-356 (1996).

4. Roessler, E. et al. Nature Genet. 14, 357-360 (1996) ecular mechanism by which impaired maternal-fetal cholesterol transport could affect the development of the central nervous system.

Joachim Herz ${ }^{1}$, Thomas E. Willnow ${ }^{2}$ \& Robert V. Farese, $\mathrm{Jr}^{3}$

5. Salen, G. et al. J. Lipid Res. 37, 1169-1180 (1996).

6. Homanies, G. E. et al. Proc. Natl. Acad. Sci. USA 90 2389-2393 (1993)

7. Farese, R. V. Jr, Ruland, S. L., Flynn, L. M., Stokowski, R. P. \& Young, S.G. Proc. Natl. Acad. Sci. USA 92
'Department of Molecular Genetics, University of Texas Southwestern Medica/ Center, Dallas, Texas 75235, USA. ${ }^{2}$ Max-Delbruck-Center, FranzGross-Haus 134D, Wiltbergstr. 50, 13125 BerlinBuch, Germany. ${ }^{3}$ Gladstone Institute of Cardiovascular Disease and Department of Medicine, University of California, San Francisco, California 94141, USA.

1774-1778 (1995).

8. Huang L.-S et al. J. Clin Invest 96, 2152-2161 (1995)

9. Willnow TE et al Proc Natl. Acad. Sci. USA 93 8460-8464 (1996).

10. Farese, R.V. Jr. et al. J. Lipid Res. 37, 347-360 (1996)

\title{
International collaboration in genetics research
}

Sir - With reference to the letter by V.L. Nimgaonkar (June 1996, page 142) ${ }^{1}$, we note that though it is undesirable to "impose cumbersome rules by an inflexible bureaucracy", the rights of subjects who have donated their genetic material and the populations they represent must be protected. Several instances of exploitation ${ }^{2,3}$ and a "scramble" to collect DNA samples before the country (India) 'tightens its laws' have indicated that scientists in India have been approached by scientists abroad to send blood samples from indigenous populations or patients with rare medical disorders. Illegal or unauthorised transfer of DNA from ethnic groups and patients has also been reported in the Indian lay press ${ }^{4}$. These allegations cannot be dismissed easily as 'until now the exchange of samples has been made on more pragmatic-and less formal grounds, involving for example either token 'gifts' in return or medical supplies and treatment ${ }^{5}$. Countries with large, well studied populations may turn out to be 'genetic goldmines.... [but] ethical and economic problems [will be] an inescapable feature of genetic research'6 .

The statement issued by UNESCO after the South-North Genome Conference notes that the ethnic diversity of India provides an opportunity to gain insights into human genetics but emphasizes protection of the interests of developing nations and their populations. It is, therefore, appropriate that the national government should monitor, and if necessary, proscribe certain kinds of usage or traffic. The procedures for international sharing of genetic material are not onerous, hence we are extremely critical of those who would choose to 'bypass the regulatory bodies entirely' ${ }^{\text {'. }}$. Scientific, consumer and public groups have been pressing for more stringent safeguards and there is an urgent need to make timely decisions regarding this matter.

Rather than simply export DNA or cell lines, a more fruitful approach would be to set up modern facilities in the host country and allow exchange of DNA with other countries for standardization of techniques and comparison. The large scientific community, including geneticists, competent medical practitioners and a network of hospitals and health centers make this a workable proposition in India. Source material could be managed at central laboratories, and if desired, be made available to international collaborators with due protection. Many international collaborations have been equitable, but others have not - nor have they been respectful of the interests of the source population ${ }^{3,5,7}$.

As a team of scientists, we are engaged in an effort to set up a multi-centre genetic study of psychiatric disorders in India with American collaboration, and with respect to institutional safeguards, we feel the concern of Nimgaonkar - that such a process may "hinder equitable collaboration" - is misplaced. The intent of this initiative is to set up a state-of-the-art laboratory for genetic research in India with technical input from collaborators in the United States in linking multiple sites in India through an electronic network. All blood samples will remain in India and analysed here. For cross-laboratory comparisons alone, samples will be exchanged in both directions with proper documentation. The intellectual property rights will be protected with a majority share of the patent, if any, being held by the collaborating Indian sites and $20 \%$ of the benefits accruing from such a patent being used by individual institutions to develop better services for the population that provided the genetic material. We hope that this will serv as an important centre for manpower devel opment in the field and as a model for othe disorders in India. In the light of previou: problems, proposals need to be carefully screened and monitored and explicit guide. lines developed for international collabora. tive research. The Government of India anc its respective agencies are already engagec in this exercise. This will strengthen the process of timely approval of such collabo. rative ventures.

Somnath Chatterji', Sanjeev Jain', Samir K. Brahmachari²,

Partha Majumder ${ }^{3}$ \& Theodore Reich ${ }^{4}$ 'Department of Psychiatry, National Institute of Mental Health and NeuroSciences (NMMHANS), Bangalore - 560029, india. ${ }^{2}$ Molecular Biophysics Unit, Indian Institute of Science, Bangalore, India. ${ }^{3}$ Division of Anthropometrics and Human Genetics, Indian Statistical institute, Calcutta, India. ${ }^{4}$ Department of Psychiatry and Genetics, Washington University School of Medicine, St. Louis, Missouri, USA.

1. Nimgaonkar, V.L. Nature Genet. 13, 142 (1996)

2. Editorial. Nature Genet. 12, 339-340 (1996).

3. Jayaraman, K.S. Nature 381, 13 (1996).

4. The Economic Times, Bangalore, India, 12 february 1996.

5. Dickson, D. Nature 381, 11-14 (1996).

6. Cohen, B. Nature 381, 12 (1996).

7. Mukerjee, M. Scientific Am. 274, 4, 22-26 (1996).

PAX6 missense mutation in isolated foveal hypoplasia

Nature Genetics 13, 141-142 (1996).

In the July issue, the numbering for the arginine-to-cysteine mutation (R125C) stated in the text is incorrect, and should read $\mathrm{R} 128 \mathrm{C}$. The numbering of other variants is not affected, however. 